\title{
Central Aortic Blood Pressure and Pulse Wave Velocity as Additional Markers in Patients with Hypertension
}

${ }^{1}$ Ravi R Kasliwal, ${ }^{2}$ Kushagra Mahansaria, ${ }^{3}$ Manish Bansal

\begin{abstract}
Arterial stiffness is a pathological manifestation of cumulative vascular damage resulting from various known and unknown vascular risk factors. Central aortic pressure and pulse wave velocity are the two most commonly used and the most informative non-invasive measures of arterial stiffness. Numerous studies have documented incremental value of these measures in a variety of clinical conditions, most notably, hypertension. In hypertensive subjects, assessment of arterial stiffness not only provides incremental information about vascular risk, it also helps in guiding therapeutic decision making and serves as a tool for monitoring response to antihypertensive therapy.
\end{abstract}

Keywords: Arterial stiffness, Arteriosclerosis, Subclinical atherosclerosis, Vascular damage.

How to cite this article: Kasliwal RR, Mahansaria K, Bansal M. Central Aortic Blood Pressure and Pulse Wave Velocity as Additional Markers in Patients with Hypertension. Hypertens J 2015;1(2):73-82.

\section{Source of support: Nil}

Conflict of interest: None

\section{INTRODUCTION}

Cardiovascular diseases (CVDs) are among the major killers in the modern world and the last few decades have seen an unprecedented increase in the incidence and prevalence of CVDs, particularly in low-income and low-middle income economies such as India. ${ }^{1,2}$ To combat the global burden of mortality and morbidity due to CVDs, several risk assessment tools have been developed to guide treatment and preventive measures at a population level..$^{3-12}$ These risk assessment tools take various known risk factors into consideration, including hypertension (HTN), diabetes mellitus (DM), smoking,

\footnotetext{
${ }^{1}$ Chairman, ${ }^{2}$ Senior Resident, ${ }^{3}$ Senior Consultant

${ }^{1}$ Department of Clinical and Preventive Cardiology, MedantaThe Medicity, Gurgaon, Haryana, India

2,3 Department of Cardiology, Medanta-The Medicity, Gurgaon Haryana, India
}

Corresponding Author: Ravi R Kasliwal, Chairman Department of Clinical and Preventive Cardiology, Room No 9 3rd Floor, Medanta-The Medicity, Sector 38, Gurgaon-122001 Haryana, India, Phone: 91-124-4141414, e-mail: rrkasliwal@ hotmail.com obesity, family history, age and gender; among others. One major limitation of these risk assessment tools is that while they can successfully predict the probability of an individual developing CVD, they cannot accurately identify the individuals who are actually going to develop CVDs. This is mainly because the relationship between the vascular risk factors and development of atherosclerosis is imperfect, and also because of the fact that the risk assessment tools take into consideration only the known risk factors, leaving room for the yet unknown risk factors to cause vascular damage. This has prompted research into developing modalities for directly identifying vascular damage at a subclinical stage to better guide CVD prevention and treatment strategies. ${ }^{13}$ These include flow-mediated dilation, finger plethysmography, digital thermal monitoring, pulse wave analysis (PWA), pulse wave velocity (PWV) assessment, pulse contour analysis, carotid wall distensibility coefficient, carotid intima-media thickness (CIMT) ${ }_{1}^{14-19}$ ankle brachial index (ABI) ${ }^{20,21}$ coronary calcium score (CCS) ${ }^{11,22-29}$ etc.

Hypertension is one of the major risk factors that contribute to the development of CVDs. ${ }^{30,31}$ Significant reduction in cardiovascular (CV) mortality due to an effective battle against high blood pressure (BP) may be considered one of the greatest medical success stories of the past century. ${ }^{32}$ For these reasons, measurement of brachial BP has become embedded in routine clinical assessment throughout the world and a reduction in the same taken as a surrogate marker for the reduction of the burden of CVDs. ${ }^{33}$

However, over the past 20 to 30 years, there has been a significant improvement in our knowledge of vascular hemodynamics and this has dramatically changed the approach to hypertensive patients. There has been an increasing recognition of the value of arterial stiffness as a marker of vascular damage, particularly in patients with HTN. Hypertension is the most important contributor of arterial stiffness and the reverse is also true with arterial stiffness being the most important mechanism responsible for $\mathrm{CV}$ damage resulting from HTN. This review summarizes the present evidence supporting the use of arterial stiffness measures, such as PWV and central aortic pressure as predictive markers for 
subclinical vascular damage in hypertensive subjects and their role in guiding BP management.

\section{Arterial Stiffness}

A delicate balance between the structural and cellular components that make up the vascular tree is responsible for proper functioning. Conditions like ageing, HTN, $\mathrm{DM}$, chronic kidney disease (CKD), atherosclerosis and other pathological conditions can disrupt this balance through various mechanisms and lead to reduced arterial distensibility, a condition defined as arterial stiffening.

On a pathological level, arterial stiffness can be described as a sum of (a) passive stiffness ${ }^{34}$ characterized by dysfunction of elastin and collagen fibers, and (b) active stiffness ${ }^{35}$ characterized by dysfunction at a cellular level including endothelial dysfunction and vascular smooth muscle cell (VSMC) alterations. ${ }^{36}$ While, inflammation causes elastin fiber loss, calcification and decreased nitric oxide production contributing to increased arterial age and stiffness; ${ }^{37}$ formation of advanced glycation end products causes irreversible protein glycation of collagen fibers leading to formation of dysfunctional collagen, ${ }^{38,39}$ that are structurally inadequate. ${ }^{40}$
At the cellular level, active stiffness is influenced by the VSMC tone, which itself is affected by vascular mediators such as Angiotensin $\mathrm{II}_{1}{ }^{41}$ endothelin, ${ }^{42}$ oxidant stress $^{43}$ and nitric oxide. Hormonal conditions like chronic hyperglycemia and hyperinsulinemia stimulate the renin-angiotensin-aldosterone system and lead to over expression of angiotensin type I receptor in vascular tissue ${ }^{44}$ promoting development of wall hypertrophy and fibrosis, ${ }^{45}$ thus contributing to arterial stiffening.

As most of these pathophysiological mechanisms are commonly triggered in patients with HTN increased arterial stiffness is a commonly encountered vascular abnormality in hypertensive patients.

\section{Anatomy and Physiology of a Pulse Wave (Figs 1A and B)}

Arterial pressure waveform at any point in the vascular tree is a composite of two distinct components: the forward pressure wave and the reflected pressure wave. ${ }^{46}$ The forward wave is the BP wave originating from the interaction between the left ventricular ejection activity and the mechanical properties of large arteries, while the reflected wave is the wave returning from the peripheries.

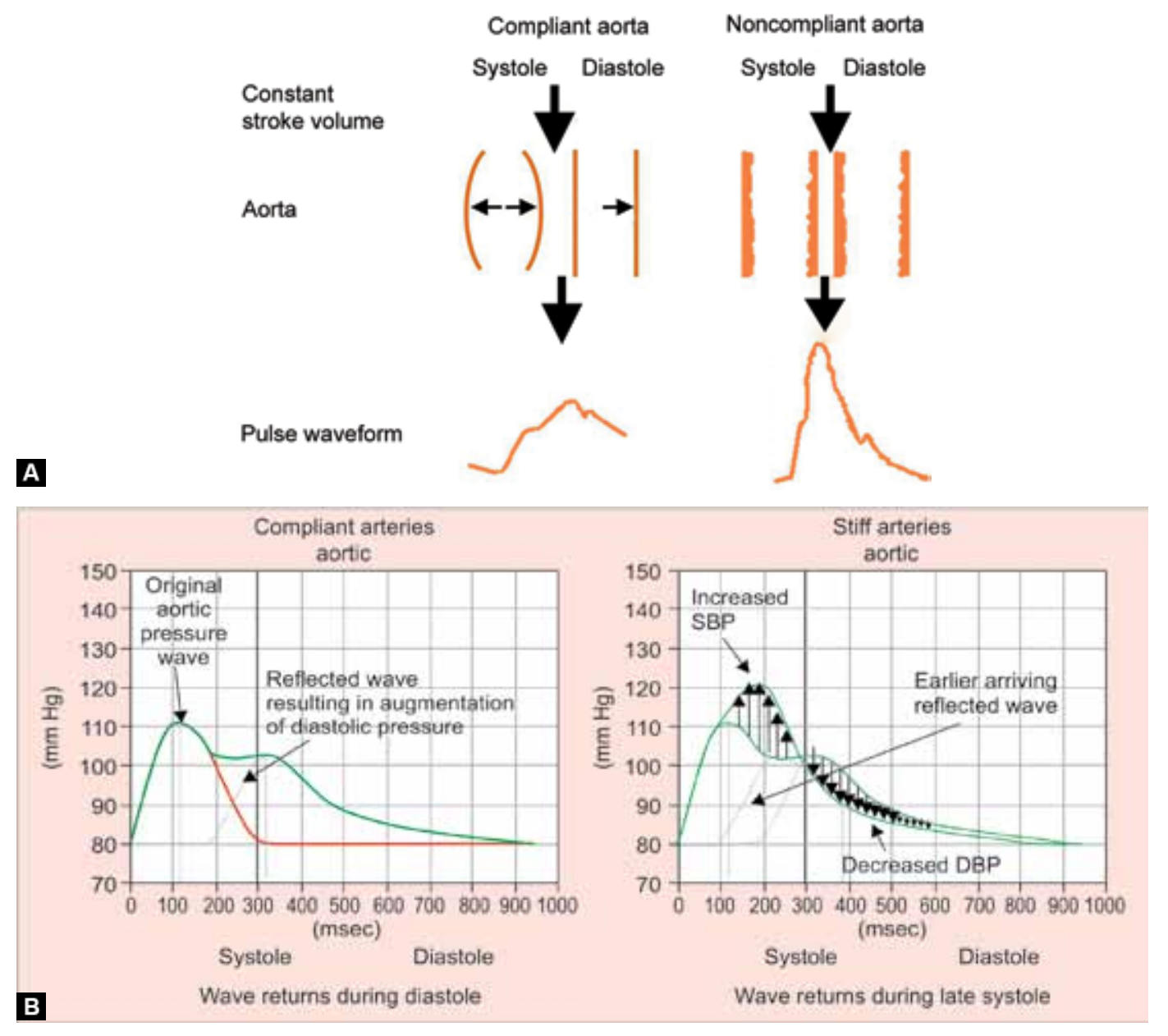

Figs 1A and B: Factors determining central aortic pressure: (A) Effect of aortic compliance on central aortic pressure, and (B) effect of peripheral arterial stiffness on central aortic pressure 
In healthy subjects the main reflection sites of the $\mathrm{CV}$ system are the arterial bifurcations and the terminal arterioles, which define the systemic vascular resistance. In normal vessels, the reflected wave tends to arrive back at the aortic root during diastole and thus helps in maintaining diastolic BP without significantly increasing systolic BP. However, in the stiff arteries, pressure pulse wave travels at faster speed and therefore the reflected wave arrives back at the central arteries earlier, during systole, adding to the forward wave and augmenting the systolic pressure, ${ }^{47}$ while diastolic pressure falls. These changes in central aortic systolic BP and diastolic BP are further augmented by the progressive loss of the 'buffer function' of aorta on the cardiac output as the aorta stiffens. ${ }^{48}$ The increase in aortic systolic BP increases cardiac afterload whereas the reduction in aortic diastolic BP levels hampers coronary blood flow. ${ }^{49}$ Accordingly, central aortic pressure is the main factor determining the development of left ventricular hypertrophy seen with arterial hypertension. ${ }^{50,51}$

\section{Measurement of Arterial Stiffness}

As mentioned earlier, technological advances have enabled clinicians to measure arterial stiffness noninvasively through various methods. The measurement of PWV and central aortic PWA are generally accepted as noninvasive, robust, and reproducible methods to determine arterial stiffness. ${ }^{52,53}$ Carotid artery pressure is often used as a surrogate for aortic pressure because of the close proximity of these arterial sites.

\section{Pulse Wave Velocity}

Pulse wave velocity (PWV) is the velocity at which the pressure pulse wave travels along the arterial system. Since the pulse wave travels at a faster speed in the

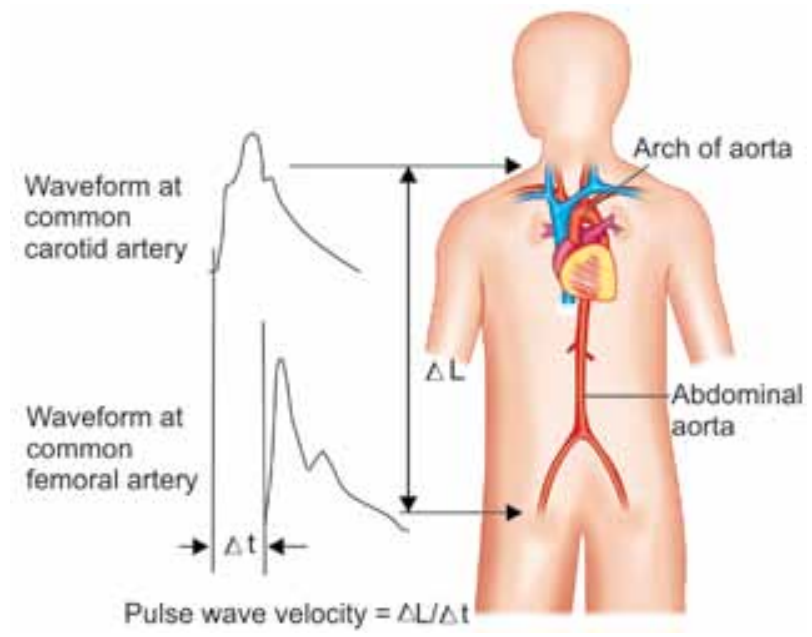

Fig. 2: 'Foot-to-foot' method for noninvasive measurement of carotid-femoral pulse wave velocity. $\Delta t$, the time delay between the arrival of pulse at common carotid artery and at the femoral artery; $\Delta \mathrm{L}$, distance between the two measurement points stiffer arteries, higher PWV indicates increased arterial stiffness. ${ }^{54}$ Pulse wave velocity is commonly measured using the 'foot to foot method' in which pulse waveforms are recorded at two different points in the vascular system and the time delay between the feet of each pressure waveform is recorded (Fig. 2). The distance between these two points divided by the time difference provides the PWV within that segment.

Of the various segments of the arterial system, carotidfemoral PWV is considered to be the gold standard as it, being closest to the aorta, best reflects aortic stiffness and has the maximum epidemiological evidence-base to support its use. ${ }^{55-58}$ Brachial-ankle PWV is another extensively studied PWV measurement and is an excellent alternative when carotid-femoral PWV is not available. ${ }^{52,59,60}$ A number of devices based on pressure sensors (e.g. Periscope ${ }^{\circledR}$, Complior $^{\circledR}$, PulsePen ${ }^{\circledR}$ or SphygmoCor $\left.{ }^{\circledR}\right)$, echotracking (WallTrack $^{\circledR}$ or Artlab ${ }^{\circledR}$ ) or Doppler ultrasound are available for measurement of PWV in clinics.

\section{Central Aortic Pulse Waveform Analysis}

Pulse wave analysis involves identification and analysis of different components of the central pressure waveform. ${ }^{61}$ As mentioned earlier, arterial stiffness augments both the forward pulse wave and the reflected wave. The extent of augmentation of systolic pressure in the central aorta provides a composite estimate of wave reflection and systemic arterial stiffness and is commonly expressed as augmentation index (AIx) (Fig. 3). Augmentation index is the difference between the 2nd and 1st systolic peaks divided by the central aortic pulse pressure (PP)

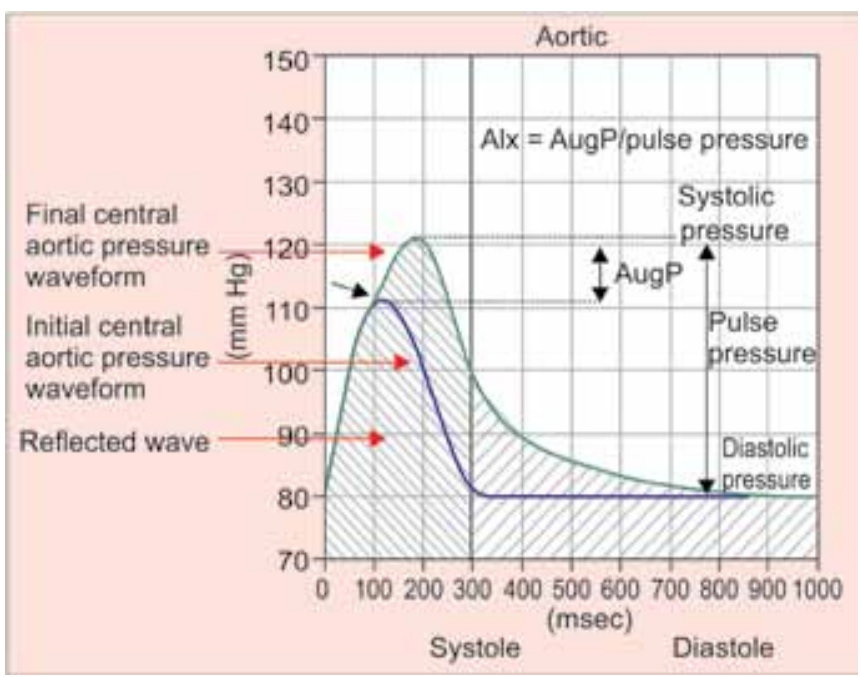

Fig. 3: Central aortic pressure waveform depicting different components. Augmentation pressure (AugP) is the difference between the initial aortic systolic pressure (early systolic inflection, bold arrow) and the final aortic systolic pressure. Augmentation index (Alx) is calculated as the ratio of augmentation pressure to central aortic pulse pressure (in percent) 
and expressed as percentage. ${ }^{62}$ Central AIx is derived noninvasively from the radial pressure wave using a mathematical fourier transfer function. ${ }^{63}$ It has been described as a measure of the timing and magnitude of pressure wave reflections from the peripheral circulation and their superimposition on the incident pressure wave. In effect, central AIx is the percentage of central PP attributable to pressure wave reflections.

\section{Clinical Significance of Measuring Central Aortic Pressure and Arterial Stiffness}

\section{Prediction of Cardiovascular Risk}

A meta-analysis ${ }^{64}$ of 11 longitudinal studies found that the age and risk factor adjusted pooled relative risk (RR) of total CV events was 1.088 for a $10 \mathrm{~mm} \mathrm{Hg}$ increase of central systolic pressure, 1.137 for a $10 \mathrm{~mm} \mathrm{Hg}$ increase of central PP, and 1.318 for a $10 \%$ absolute increase of central AIx. Furthermore, it was found that a 10\% increase of central AIx was associated with a RR of 1.384 for all-cause mortality. Another meta-analysis of 17,635 participants ${ }^{65}$ found that the pooled age and sex-adjusted hazard ratios (HRs) per 1-SD change in loge aPWV were 1.35 for coronary heart disease, 1.54 for stroke, and 1.45 for CVD. After adjusting for conventional risk factors, aPWV remained a predictor of coronary heart disease (HR: 1.23), stroke (HR: 1.28) and CVD events (HR: 1.30).

A number of studies have shown that measures of arterial stiffness predict risk of CV mortality, total mortality, fatal and nonfatal coronary events and fatal strokes in different patient subsets including hypertensives, ${ }^{66-68}$ diabetics, ${ }^{69}$ elderly subjects, ${ }^{70,71}$ patients with end-stage renal disease $\mathrm{e}^{72}$ as well as in the general population. ${ }^{73,74}$ Central AIx and PP have shown an independent predictive value for all-cause mortality in ESRD patients ${ }^{75,76}$ and CV events in hypertensives ${ }^{67,77}$ and patients with coronary disease and those undergoing $\mathrm{PCI}^{78}$ Among the Indian population subsets too, various studies have demonstrated relationship of arterial stiffness to various conventional and nonconventional CV risk factors, such as diabetes, ${ }^{79,80}$ hypertension, ${ }^{80-82}$ tobacco use, ${ }^{83}$ obesity $^{84-86}$ and metabolic syndrome. ${ }^{87}$ More importantly, increased arterial stiffness has also been noted in children ${ }^{88}$ and young adults ${ }^{84}$ and associated with incident coronary artery disease $(\mathrm{CAD})^{89,90}$ and peripheral arterial occlusive disease. ${ }^{91}$

Based on the available evidence, it has been suggested that increased arterial PWV can serve as a useful tool for screening for presence of coronary atherosclerosis. ${ }^{89,90}$ However, for this purpose, it is helpful to combine it with CIMT. Presence of both normal brachial-ankle PWV and normal CIMT has been found to have high negative predictive value for excluding coronary atherosclerosis. Conversely, when both PWV and CIMT are increased, there is high probability of co-existing CAD. 89,90

The assessment of arterial stiffness can also be used for monitoring the impact of various therapeutic measures on vascular structure and function. Several nonpharmacological treatments, such as exercise training, ${ }^{92}$ dietary changes including weight loss, ${ }^{93}$ low salt diet ${ }^{94}$ moderate alcohol consumption, ${ }^{95}$ fish oil ${ }^{96}$ etc. have been shown to reduce arterial stiffness. The effect of various antihypertensive drugs on arterial stiffness is discussed below.

\section{Central Aortic Pressure for Guiding Antihypertensive Treatment}

A study by McEniery et a ${ }^{97}$ in $>10,000$ subjects demonstrated a substantial overlap of central and brachial BP between categories of hypertension. Over $70 \%$ of individuals categorized as having 'high-normal' brachial systolic pressure based on Joint European Cardiology and Hypertension Society guidelines ${ }^{56}$ had similar aortic pressures corresponding to those with stage 1 hypertension. Moreover, $30 \%$ of males and $10 \%$ of females with normal brachial BP had aortic pressures in common with individuals with stage 1 hypertension.

Central pressure is more closely correlated with widely accepted surrogate measures of CV risk, such as CIMT $^{98,99}$ and left ventricular mass, ${ }^{100-102}$ than brachial pressure in several cross-sectional studies, as well as a few prospective studies. In the pREterax in regression of Arterial Stiffness in a contrOlled double-bliNd (REASON) study, ${ }^{103}$ regression of left ventricular mass was more strongly related to changes in central compared with brachial pressure and, after adjustment, only central pressure remained predictive. Similarly, with antihypertensive therapy, the reduction in CIMT has been shown to relate better with the fall in central pressure than the fall in brachial BP. ${ }^{104,105}$

These findings have important clinical implications because, by focusing only on brachial BP at present, we may be over-treating some subjects with relatively low central pressures, and under-treating others who have elevated central pressure, just because their have brachial systolic pressures are within currently recommended therapeutic ranges. Moreover, different antihypertensive drugs may affect central aortic pressure differentially, ${ }^{103,106-108}$ and therefore, lead to dissimilar CV benefits.

The Anglo-Scandinavian cardiac outcomes trial $(\mathrm{ASCOT})^{109}$ showed a greater reduction in CV events among patients treated with a calcium channel blocker 
amlodipine compared with patients treated with the $\beta$-blocker atenolol, without any difference being noted in the reduction of brachial systolic BP values between the groups treated. The potential mechanism underlying these differences was explained by the landmark conduit artery functional endpoint (CAFE) study, ${ }^{106}$ which was a sub-study of the larger ASCOT trial. It showed that the two antihypertensive regimens had differential effects on peripheral BP and central aortic pressure. A greater decrease in central systolic BP and in central PP occurred in subjects randomized to amlodipine $+/-$ perindopril as compared to those treated with bendroflumetiazide +/- atenolol, in spite of similar reductions in brachial systolic BP. Based on these finding, the authors concluded that the greater reduction in CV events in the group treated with amlodipine/perindopril was likely to be due to a greater effect of these drugs in lowering central systolic BP. A similar finding was seen in the REASON study ${ }^{103,107}$ also, which showed a significant reduction in LV mass and a greater decrease in central pressure after 1 year of treatment with low dose perindopril + in dapamide combination as compared to atenolol. Other studies including the heart outcomes prevention evaluation (HOPE) study ${ }^{110,111}$ and the LIFE study ${ }^{112,113}$ have also shown that the clinical benefit of treatment with ACEIs (ramipril) or ARBs (losartan) extend beyond just reduction in brachial $\mathrm{BP}$ only and may be attributed to reduced target organ damage resulting from a reduction in arterial stiffness and central aortic pressure. The results of these studies lend support to the hypothesis that an inadequate reduction in central pressure may be associated with an adverse outcome. To date, antihypertensive drugs have been shown to exert variable effects on PWV and arterial stiffness (Table 1). Further research work is needed to categorize anti-hypertensive drugs on the basis of their actions on PWV and arterial stiffness.

\section{Reproducibility of Measures of Arterial Stiffness}

A screening test should be reliable, reproducible, easy to perform and cost effective to warrant its use in regular clinical practice. One of the first studies analyzing the reproducibility of PWA was published by Wilkinson

Table 1: Effects of anti-hypertensive drugs on pulse wave velocity and arterial stiffness

\begin{tabular}{l} 
- Diuretics $\leftrightarrow$ \\
- CCBs $\downarrow$ \\
- ACEls $\downarrow$ \\
- ARBs $\downarrow$ \\
- Vasodilating $\beta$-blockers $\downarrow$ \\
- Angiotensin receptor/neprilysin $\downarrow$ inhibitor (parameter study) \\
\hline
\end{tabular}

et al. ${ }^{114}$ They found that PWA was a simple and reproducible technique with which to measure PWV and AIx with very little interobserver variability. Recently published data from the atherosclerosis risk in communities study (ARIC) ${ }^{115}$ found that the repeatability of PWV was under acceptable parameters for all PWV measures in a multicenter, populationbased study of older adults and supported its use in epidemiologic studies. However, they also recommended that quantifying PWV measurement variation is critical for applications to risk assessment and stratification and eventual translation to clinical practice. Another study ${ }^{116}$ comparing the cost effectiveness of noninvasive assessment of central BP against brachial BP for diagnosis of HTN found central BP monitoring to be more cost effective for both men and women across all age groups.

\section{Future Directions}

A growing body of evidence suggests that central systolic BP and central PP are accurate markers of the actual pressure load imposed on the left ventricle and are better measurements than peripheral systolic BP and peripheral PP. ${ }^{117}$ In addition, numerous studies suggest that parameters of central hemodynamics predict the occurrence of $\mathrm{CV}$ events independently of brachial $\mathrm{BP}$ values. $^{52}$

For a biomarker to be integrated into clinical practice, it should meet the following criteria: ${ }^{118}$ (a) it must differ between subjects with and without outcomes; (b) it must predict future outcomes in prospective studies; (c) it must add predictive information on top of established risk markers; (d) it must be cost efficient; (e) it must reclassify patients' predicted risk to a sufficient extent; and (f) its use must improve outcomes when evaluated in a randomized study. So far, measurement of arterial stiffness and central BP have fulfilled criteria (a) to (d) sufficiently and more research is being published every day supporting value of PWV, PWA and AIx as markers of CV risk. ${ }^{119,120}$ However, more evidence is needed to determine if these markers also satisfy the criteria (e) and (f).

Of particular note is a prospective, randomized, open-label, blinded end point (PROBE) study by Sharman et $\mathrm{al}^{121}$ which addressed the use of central aortic BP as a guide for treatment. Patients were randomized to treatment decisions that were guided by best-practice usual care for BP (using office BP, home BP, and 24-hours ambulatory $\mathrm{BP}$ ) or the addition of a central aortic $\mathrm{BP}$ intervention (measured using radial applanation tonometry). A key element of the study was the guidelines and recommendations given to the treating practitioners for titration of therapy. The 5 recommendation scenarios describe the combination of central aortic BP with the 
other BP measures (office, home, 24-hour ambulatory BP) so as to increase, maintain, or decrease the therapy. They concluded that guidance of hypertension management with central BP resulted in a significantly different therapeutic pathway than conventional cuff BP, with less use of medication to achieve BP control and no adverse effects on left ventricular mass, aortic stiffness, or quality of life. However, the implications of these observations with respect to the long-term CVD risk remain to be proven.

The 2010 guidelines of the ACC/AHA for assessment of CVD risk in asymptomatic adults ${ }^{122}$ did not recommend routine measurement of PWV for CVD risk assessment in asymptomatic adults, mainly on the basis of the lack of evidence supporting the ability of PWV to reclassify risk in asymptomatic adults or general population. Later on, after the publication of few large studies mentioned earlier, the recent $2013 \mathrm{ESH} / \mathrm{ESC}$ guidelines for the management of arterial hypertension ${ }^{56}$ have recommended measurement of PWV for evaluation of subclinical organ damage in hypertensive patients (recommendation class IIa, Level of Evidence: B), and suggested a cutoff of $10 \mathrm{~m} / \mathrm{s}$ to discriminate between normal aortic elasticity and aortic stiffening. ${ }^{123}$ However, they also state that although the measurement of central aortic BP is of interest in terms of analyses for elucidating mechanisms related to pathophysiology, pharmacology, and therapeutics, further investigations are needed before central aortic BP can be recommended for routine clinical use. Indeed, trials are required to assess the impact of arterial stiffness guided management on hard CVD end points, where subjects are followed up for a longer period. At the same time, it is also important to establish normal ranges of various arterial stiffness parameters for different ethnic groups, a key prerequisite for wider use of these markers in clinical practice. However, as the new research emerges to address these pending issues, the next decade could very well be the decade of "arterial de-stiffening. ${ }^{68}$

\section{REFERENCES}

1. Mozaffarian D, Benjamin EJ, Go AS, et al. Heart disease and stroke statistics-2015 update: a report from the American Heart Association. Circulation 2015;131(4):e29-322.

2. Reddy KS. At the heart of global development. J Am Coll Cardiol 2014;64(4):416-417.

3. Wilson PW, D'Agostino RB, Levy D, Belanger AM, SilbershatzH, Kannel WB. Prediction of coronary heart disease using risk factor categories. Circulation 1998;97(18):1837-1847.

4. D'Agostino RB Sr, Vasan RS, Pencina MJ, et al. General cardiovascular risk profile for use in primary care: the Framingham heart study. Circulation 2008;117(6):743-753.

5. Assmann G, Cullen P, Schulte H. Simple scoring scheme for calculating the risk of acute coronary events based on the 10-year follow-up of the prospective cardiovascular munster (procam) study. Circulation 2002;105(3):310-315.

6. World health organization. Prevention of cardiovascular disease guidelines for assessment and management of cardiovascular risk. Geneva: WHO. 2007. p. 86.

7. Conroy RM, Pyorala K, Fitzgerald AP, et al. Estimation of 10-year risk of fatal cardiovascular disease in Europe: the score project. Eur Heart J 2003;24(11):987-1003.

8. Hippisley-Cox J, Coupland C, Vinogradova Y, et al. Predicting cardiovascular risk in England and Wales: prospective derivation and validation of qrisk2. BMJ 2008;336(7659): 1475-1482.

9. Hippisley-Cox J, Coupland C, Vinogradova Y, Robson J, May M, Brindle P. Derivation and validation of qrisk, a new cardiovascular disease risk score for the united kingdom: prospective open cohort study. BMJ 2007;335(7611):136.

10. Hippisley-Cox J, Coupland C, Vinogradova Y, Robson J, Brindle P. Performance of the qrisk cardiovascular risk prediction algorithm in an independent UK sample of patients from general practice: a validation study. Heart 2008;94(1):34-39.

11. Goff DC Jr, Lloyd-Jones DM, Bennett G, et al. 2013 ACC/AHA guideline on the assessment of cardiovascular risk: a report of the American College of Cardiology/American Heart Association task force on practice guidelines. Circulation 2014;129(25 Suppl 2):S49-73.

12. Joint British Societies' consensus recommendations for the prevention of cardiovascular disease (JBS3). Heart 2014;100 (Suppl 2):ii1-ii67.

13. Taylor AJ, Merz CN, Udelson JE. 34th bethesda conference: Executive summary--can atherosclerosis imaging techniques improve the detection of patients at risk for ischemic heart disease? J Am Coll Cardiol 2003;41(11):1860-1862.

14. Lorenz MW, Markus HS, Bots ML, Rosvall M, Sitzer M. Prediction of clinical cardiovascular events with carotid intima-media thickness: A systematic review and metaanalysis. Circulation 2007;115(4):459-467.

15. Folsom AR, Kronmal RA, Detrano RC, et al. Coronary artery calcification compared with carotid intima-media thickness in the prediction of cardiovascular disease incidence: the multi-ethnic study of atherosclerosis (mesa). Arch Int Med 2008;168(12):1333-1339.

16. O'Leary DH, Bots ML. Imaging of atherosclerosis: Carotid intima-media thickness. Eur Heart J 2010;31(14):1682-1689.

17. Lorenz MW, von Kegler S, Steinmetz H, Markus HS, Sitzer M. Carotid intima-media thickening indicates a higher vascular risk across a wide age range: prospective data from the carotid atherosclerosis progression study (CAPS). Stroke 2006;37(1):87-92.

18. Stein JH, Korcarz CE, Hurst RT, et al. Use of carotid ultrasound to identify subclinical vascular disease and evaluate cardiovascular disease risk: a consensus statement from the American society of echocardiography carotid intima-media thickness task force endorsed by the society for vascular medicine. J Am Soc Echocardiogr 2008 Feb;21(2):93-111.

19. Postley JE, Perez A, Wong ND, Gardin JM. Prevalence and distribution of subclinical atherosclerosis by screening vascular ultrasound in low and intermediate risk adults: the New York physicians study. J Am Soc Echocardiogr 2009 Oct;22(10):1145-1151.

20. Frolow M, Drozdz A, Kowalewska A, Nizankowski R, Chlopicki S. Comprehensive assessment of vascular health 
in patients; towards endothelium-guided therapy. Pharmacol Reports 2015;67(4):786-792.

21. Widlansky ME, Gokce N, Keaney JJF, Vita JA. The clinical implications of endothelial dysfunction. J Am College Cardiol 2003;42(7):1149-1160.

22. Greenland $\mathrm{P}$, Bonow RO, Brundage $\mathrm{BH}$, et al. ACCF/AHA 2007 clinical expert consensus document on coronary artery calcium scoring by computed tomography in global cardiovascular risk assessment and in evaluation of patients with chest pain: a report of the American College of Cardiology Foundation clinical expert consensus task force (ACCF/AHA writing committee to update the 2000 expert consensus document on electron beam computed tomography) developed in collaboration with the society of atherosclerosis imaging and prevention and the society of cardiovascular computed tomography. J Am Coll Cardiol 2007;49(3):378-402.

23. Greenland P, LaBree L, Azen SP, Doherty TM, Detrano RC. Coronary artery calcium score combined with Framingham score for risk prediction in asymptomatic individuals. JAMA 2004;291(2):210-215.

24. Taylor AJ, Bindeman J, Feuerstein I, Cao F, Brazaitis M, O'Malley PG. Coronary calcium independently predicts incident premature coronary heart disease over measured cardiovascular risk factors: mean 3-year outcomes in the prospective army coronary calcium (PACC) project. J Am Coll Cardiol 2005;46(5):807-814.

25. Arad Y, Goodman KJ, Roth M, Newstein D, Guerci AD. Coronary calcification, coronary disease risk factors, c-reactive protein, and atherosclerotic cardiovascular disease events: The st. Francis heart study. J Am Coll Cardiol 2005;46(1):158-165.

26. Kondos GT, Hoff JA, Sevrukov A, et al. Electron-beam tomography coronary artery calcium and cardiac events: a 37-month follow-up of 5635 initially asymptomatic low- to intermediate-risk adults. Circulation 2003;107(20):2571-2576.

27. Vliegenthart R, Oudkerk M, Hofman A, et al. Coronary calcification improves cardiovascular risk prediction in the elderly. Circulation 2005;112(4):572-577.

28. LaMonte MJ, FitzGerald SJ, Church TS, et al. Coronary artery calcium score and coronary heart disease events in a large cohort of asymptomatic men and women. Am J Epidemiol 2005;162(5):421-429.

29. Folsom AR, Kronmal RA, Detrano RC, et al. Coronary artery calcification compared with carotid intima-media thickness in the prediction of cardiovascular disease incidence: the multi-ethnic study of atherosclerosis (MESA). Arch Intern Med 2008;168(12):1333-1339.

30. Kearney PM, Whelton M, Reynolds K, Muntner P, Whelton PK, He J. Global burden of hypertension: analysis of worldwide data. Lancet 2005;365(9455):217-223.

31. Mills KT, Bundy JD, Kelly TN, et al. Global burden and control of hypertension in 2010: Analysis of population-based studies from 89 countries. Circulation 2015;131(Suppl 1):A32.

32. Salvi P, Bellasi A, Di Iorio B. Does it make sense to measure only the brachial blood pressure? Blood Purification 2013;36(1):21-25.

33. McEniery CM, Cockcroft JR, Roman MJ, Franklin SS, Wilkinson IB. Central blood pressure: current evidence and clinical importance. Eur Heart J 2014;35(26): 1719-1725.
34. Lacolley P, Challande P, Osborne-Pellegrin M, Regnault V. Genetics and pathophysiology of arterial stiffness. Cardiovasc Res 2009;81(4):637-648.

35. Zieman SJ, Melenovsky V, Kass DA. Mechanisms, pathophysiology, and therapy of arterial stiffness. Arterioscler Thromb Vasc Biol 2005;25(5):932-943.

36. Wolinsky H, Glagov S. Structural basis for the static mechanical properties of the aortic media. Circ Res 1964; 14(5):400-413.

37. Johnson CP, Baugh R, Wilson CA, Burns J. Age related changes in the tunica media of the vertebral artery: Implications for the assessment of vessels injured by trauma. J Clin Pathol 2001;54(2):139-145.

38. Lee AT, Cerami A. Role of glycation in aging. Ann N Y Acad Sci 1992;663:63-70.

39. Xu C, Zarins CK, Pannaraj PS, Bassiouny HS, Glagov S. Hypercholesterolemia superimposed by experimental hypertension induces differential distribution of collagen and elastin. Arterioscler Thromb Vasc Biol 2000;20(12):2566-2572.

40. Verzijl N, DeGroot J, Thorpe SR, et al. Effect of collagen turnover on the accumulation of advanced glycation end products. J Biol Chem 2000;275(50):39027-39031.

41. Dzau VJ. Significance of the vascular renin-angiotensin pathway. Hypertension 1986;8(7):553-559.

42. Yanagisawa M, Kurihara H, Kimura S, et al. A novel potent vasoconstrictor peptide produced by vascular endothelial cells. Nature 1988;332(6163):411-415.

43. Gurtner GH, Burke-Wolin T. Interactions of oxidant stress and vascular reactivity. Am J Physiol 1991;260(4 Pt 1):L207-211.

44. Nickenig G, Roling J, Strehlow K, Schnabel P, Bohm M. Insulin induces upregulation of vascular at1 receptor gene expression by post-transcriptional mechanisms. Circulation 1998;98(22):2453-2460.

45. Jesmin S, Sakuma I, Hattori Y, Kitabatake A. Role of angiotensin II in altered expression of molecules responsible for coronary matrix remodeling in insulin-resistant diabetic rats. Arterioscler Thromb Vasc Biol 2003;23(11):2021-2026.

46. O'Rourke MF. Pressure and flow waves in systemic arteries and the anatomical design of the arterial system. J Appl Physiol 1967;23(2):139-149.

47. Cohn JN, Finkelstein S, McVeigh G, et al. Noninvasive pulse wave analysis for the early detection of vascular disease. Hypertens 1995;26(3):503-508.

48. Wilkinson IB, Cockcroft JR, Webb DJ. Pulse wave analysis and arterial stiffness. J Cardiovas Pharmacol 1997;32(Suppl3): S33-37.

49. London GM, Guerin AP. Influence of arterial pulse and reflected waves on blood pressure and cardiac function. Am Heart J 1999;138(3 pt 2):S220-S224.

50. Salvi P. Pulse waves: how vascular hemodynamics affects blood pressure. Springer Science \& Business Media; 2012.

51. Nichols W, O'Rourke M, Vlachopoulos C. McDonald's blood flow in arteries: theoretical, experimental and clinical principles. CRC Press; 2011.

52. Laurent S, Cockcroft J, Van Bortel L, et al. Expert consensus document on arterial stiffness: methodological issues and clinical applications. Europ Heart J 2006;27(21): 2588-2605.

53. Narayan O, Casan J, Szarski M, Dart AM, Meredith IT, Cameron JD. Estimation of central aortic blood pressure: A systematic meta-analysis of available techniques. J Hypertens 2014;32(9):1727-1740. 
54. O'Rourke M. Arterial pressure waveforms in hypertension. Minerva Medica 2003;94(4):229-250.

55. Izzo JL. Brachial vs. Central systolic pressure and pulse wave transmission indicators: a critical analysis. Am J Hypertens 2014;27(12):1433-1442.

56. Mancia G, Fagard R, Narkiewicz K, Redon J, Zanchetti A, Bohm M, et al. 2013 ESH/ESC guidelines for the management of arterial hypertension: the task force for the management of arterial hypertension of the European Society of Hypertension (ESH) and of the European Society of Cardiology (ESC). J Hypertens 2013;31(7):1281-1357.

57. Sueta D, Yamamoto E, Tanaka T, et al. Association of estimated central blood pressure measured noninvasively with pulse wave velocity in patients with coronary artery disease. IJC Heart \& Vasculature 2015;8:52-54.

58. Xiao W-K, Ye P, Bai Y-Y, Luo L-M, Wu H-M, Gao P. [central pulse pressure but not brachial blood pressure is the predominant factor affecting aortic arterial stiffness]. Nan Fang Yi Ke Da Xue Xue Bao 2015;35(1):34-39.

59. Karamanoglu M, O'Rourke MF, Avolio AP, Kelly RP. An analysis of the relationship between central aortic and peripheral upper limb pressure waves in man. Eur Heart J 1993;14(2):160-167.

60. Shih YT, Cheng HM, Sung SH, Chuang SY, Hu WC, Chen CH. Is noninvasive brachial systolic blood pressure an accurate estimate of central aortic systolic blood pressure? Am J Hypertens 2015 Oct 5. pii: hpv164. [Epub ahead of print]

61. Pauca AL, O'Rourke MF, Kon ND. Prospective evaluation of a method for estimating ascending aortic pressure from the radial artery pressure waveform. Hypertens 2001;38(4): 932-937.

62. O'Rourke MF, Pauca A, Jiang XJ. Pulse wave analysis. Br J Clin Pharmacol 2001;51(6):507-522.

63. Chen $\mathrm{CH}, \mathrm{Nevo}$ E, Fetics B, et al. Estimation of central aortic pressure waveform by mathematical transformation of radial tonometry pressure validation of generalized transfer function. Circulation 1997;95(7):1827-1836.

64. Vlachopoulos C, Aznaouridis K, O'Rourke MF, Safar ME, Baou K, Stefanadis C. Prediction of cardiovascular events and all-cause mortality with central haemodynamics: A systematic review and meta-analysis. Eur Heart J 2010;31(15):1865-1871.

65. Ben-Shlomo Y, Spears M, Boustred C, et al. Aortic pulse wave velocity improves cardiovascular event prediction an individual participant meta-analysis of prospective observational data from 17,635 subjects. J Am College Cardiol 2014;63(7):636-646.

66. Boutouyrie P, Tropeano AI, Asmar R, et al. Aortic stiffness is an independent predictor of primary coronary events in hypertensive patients: a longitudinal study. Hypertens 2002;39(1):10-15.

67. Laurent S, Boutouyrie P, Asmar R, et al. Aortic stiffness is an independent predictor of all-cause and cardiovascular mortality in hypertensive patients. Hypertens 2001;37(5): 1236-1241.

68. Palatini P, Casiglia E, Gąsowski J, et al. Arterial stiffness, central hemodynamics, and cardiovascular risk in hypertension. Vascular Health and Risk Management 2011;7: 725-739.

69. Cruickshank K, Riste L, Anderson SG, Wright JS, Dunn G, Gosling RG. Aortic pulse-wave velocity and its relationship to mortality in diabetes and glucose intolerance: an integrated index of vascular function? Circulation 2002;106(16): 2085-2090.

70. Mattace-Raso FU, van der Cammen TJ, Hofman A, et al. Arterial stiffness and risk of coronary heart disease and stroke: the rotterdam study. Circulation 2006;113(5):657-663.

71. Sutton-Tyrrell K, Najjar SS, Boudreau RM, et al. Elevated aortic pulse wave velocity, a marker of arterial stiffness, predicts cardiovascular events in well-functioning older adults. Circulation 2005;111(25):3384-3390.

72. Blacher J, Guerin AP, Pannier B, Marchais SJ, Safar ME, London GM. Impact of aortic stiffness on survival in endstage renal disease. Circulation 1999;99(18):2434-2439.

73. Shokawa T, Imazu M, Yamamoto H, et al. Pulse wave velocity predicts cardiovascular mortality: findings from the hawaiilos angeles-hiroshima study. Circ J 2005;69(3):259-264.

74. Willum-Hansen T, Staessen JA, Torp-Pedersen C, et al. Prognostic value of aortic pulse wave velocity as index of arterial stiffness in the general population. Circulation 2006;113(5):664-670.

75. Safar ME, Blacher J, Pannier B, et al. Central pulse pressure and mortality in end-stage renal disease. Hypertens 2002;39(3):735-738.

76. London GM, Blacher J, Pannier B, Guérin AP, Marchais SJ, Safar ME. Arterial wave reflections and survival in end-stage renal failure. Hypertens 2001;38(3):434-438.

77. Asmar R, Rudnichi A, Blacher J, London GM, Safar ME. Pulse pressure and aortic pulse wave are markers of cardiovascular risk in hypertensive populations. Am J Hypertens 2001;14(2): 91-97.

78. Weber $\mathrm{T}$, Auer J, O'Rourke MF, et al. Increased arterial wave reflections predict severe cardiovascular events in patients undergoing percutaneous coronary interventions. Eur Heart J 2005;26(24):2657-2663.

79. George B, Bantwal G, Ayyar V, Mathew V. Occurrence of increased arterial stiffness in a cohort of adult patients with type 1 diabetes mellitus when compared to normoglycemic controls. J Diabetes Sci Technol 2015;9(1):138-144.

80. Kulkarni NB, Ganu MU, Godbole SG, Deo SS. Effect of age and blood pressure on surrogate markers of atherosclerosis in patients with type 2 diabetes mellitus. J Clin Diagnostic Res 2014;8(6):BC08-11.

81. Gunarathne A, Patel JV, Gammon B, Hughes EA, Lip GY. Impact of mean arterial blood pressure on higher arterial stiffness indices in South Asians compared to white Europeans. J Hypertens 2008;26(7):1420-1426.

82. Kasliwal RR, Bansal M, Mehrotra R, Trehan N. Relationship of arterial stiffness with hypertension and its management in a North-Indian population free of cardiovascular disease J Clin Prev Cardiol 2012;1(1):1-8.

83. Jain S, Mathur S, Mathur A, et al. Effect of tobacco use on arterial stiffness in community dwelling females. J Assoc Physicians India 2012;60:20-23.

84. Pandit DS, Khadilkar AV, Chiplonkar SA, Khadilkar VV, Kinare AS. Arterial stiffness in obese children: role of adiposity and physical activity. Ind J Endocrinol Metab 2014;18(1):70-76.

85. Liu JJ, Sum CF, Tavintharan S, et al. Obesity is a determinant of arterial stiffness independent of traditional risk factors in Asians with young-onset type 2 diabetes. Atherosclerosis 2014;236(2):286-291. 
86. Anoop S, Misra A, Bhardwaj S, Gulati S. High body fat and low muscle mass are associated with increased arterial stiffness in Asian Indians in North India. J Diabetes Complications 2015;29(1):38-43.

87. Pandit D, Chiplonkar S, Khadilkar A, Kinare A, Khadilkar V, Divate U. Evaluation of risk of atherosclerosis in Indian adults. J Assoc Physicians India 2013;61(5):312-316.

88. Cote AT, Phillips AA, Harris KC, Sandor GGS, Panagiotopoulos C, Devlin AM. Obesity and arterial stiffness in children: Systematic review and meta-analysis. Arteriosclerosis, Thrombosis, and Vascular Biol 2015;35(4):1038-1044.

89. Kasliwal RR, Bansal M, Bhargava K, Gupta H, Tandon S, Agrawal V. Carotid intima-media thickness and brachialankle pulse wave velocity in patients with and without coronary artery disease. Ind Heart J 2004;56(2):117-122.

90. Kasliwal RR, Bansal M, Mehrotra R, Ahlawat K, Trehan N. Comparative diagnostic accuracy of different measures of preclinical atherosclerosis for detection of atherosclerotic coronary artery disease. J Clin Prev Cardiol 2014;3(2):36-42.

91. Pradeepa R, Chella S, Surendar J, Indulekha K, Anjana RM, Mohan V. Prevalence of peripheral vascular disease and its association with carotid intima-media thickness and arterial stiffness in type 2 diabetes: the Chennai urban rural epidemiology study (CURES 111). Diab Vasc Dis Res 2014;11(3): 190-200.

92. Kingwell BA, Berry KL, Cameron JD, Jennings GL, Dart AM. Arterial compliance increases after moderate-intensity cycling. Am J Physiol Heart and Circulatory Physiol 1997;273(5 Pt 2): H2186-H2191.

93. Balkestein EJ, van Aggel-Leijssen DP, van Baak MA, StruijkerBoudier HA, Van Bortel LM. The effect of weight loss with or without exercise training on large artery compliance in healthy obese men. J Hypertens 1999;17(12 Pt 2):1831-1835.

94. Avolio AP, Clyde KM, Beard TC, Cooke HM, Ho K, O'Rourke MF. Improved arterial distensibility in normotensive subjects on a low salt diet. Arteriosclerosis, Thrombosis and Vascular Biol 1986;6(2):166-169.

95. Sierksma A, Lebrun CE, van der Schouw YT, et al. Alcohol consumption in relation to aortic stiffness and aortic wave reflections: a cross-sectional study in healthy postmenopausal women. Arteriosclerosis, Thrombosis and Vascular Biol 2004;24(2):342-348.

96. McVeigh GE, Brennan GM, Cohn JN, Finkelstein SM, Hayes RJ, Johnston GD. Fish oil improves arterial compliance in non-insulin-dependent diabetes mellitus. Arteriosclerosis, Thrombosis and Vascular Biol 1994;14(9):1425-1429.

97. McEniery CM, McDonnell B, Munnery M, et al. Central pressure: variability and impact of cardiovascular risk factors the anglo-cardiff collaborative trial II. Hypertens 2008;51(6):1476-1482.

98. Wang KL, Cheng HM, Chuang SY, et al. Central or peripheral systolic or pulse pressure: which best relates to target-organs and future mortality? J Hypertens 2009;27(3):461-467.

99. Boutouyrie P, Bussy C, Lacolley P, Girerd X, Laloux B, Laurent $S$. Association between local pulse pressure, mean blood pressure, and large-artery remodeling. Circulation 1999;100(13):1387-1393.

100. Wohlfahrt P, Wichterle D, Seidlerová J, et al. Relation of central and brachial blood pressure to left ventricular hypertrophy: The czech post-monica study. J Human Hypertens 2012;26(1): 14-19.
101. Roman MJ, Okin PM, KizerJR, LeeET, Howard BV, Devereux RB. Relations of central and brachial blood pressure to left ventricular hypertrophy and geometry: the strong heart study. J Hypertens 2010;28(2):384-388.

102. Covic A, Goldsmith DJ, Panaghiu L, Covic M, Sedor J. Analysis of the effect of hemodialysis on peripheral and central arterial pressure waveforms. Kidney Int 2000;57(6):2634-2643.

103. de Luca N, Asmar RG, London GM, O'Rourke MF, Safar ME. Selective reduction of cardiac mass and central blood pressure on low-dose combination perindopril/indapamide in hypertensive subjects. J Hypertens 2004;22(8):1623-1630.

104. Boutouyrie P, Bussy C, Tropeano A, et al. Local pulse pressure and regression of arterial wall hypertrophy during antihypertensive treatment. Celimene study. The celiprolol intima-media enalapril efficacy study. Archives des maladies du coeur et des vaisseaux 2000;93(8):911-915.

105. Boutouyrie P, Bussy C, Hayoz D, et al. Local pulse pressure and regression of arterial wall hypertrophy during long-term antihypertensive treatment. Circulation 2000;101(22):2601-2606.

106. Williams B, Lacy PS, Thom SM, et al. Differential impact of blood pressure-lowering drugs on central aortic pressure and clinical outcomes: principal results of the conduit artery function evaluation (CAFE) study. Circulation 2006;113(9):1213-1225.

107. Asmar RG, London GM, O'Rourke ME, Safar ME. Coordinators RP, Investigators. Improvement in blood pressure, arterial stiffness and wave reflections with a very-low-dose perindopril/indapamide combination in hypertensive patient a comparison with atenolol. Hypertens 2001;38(4): 922-926.

108. Morgan T, Lauri J, Bertram D, Anderson A. Effect of different antihypertensive drug classes on central aortic pressure. Am J Hypertens 2004;17(2):118-123.

109. Sever PS, Dahlöf B, Poulter NR, et al. Rationale, design, methods and baseline demography of participants of the anglo-scandinavian cardiac outcomes trial. J Hypertens 2001;19(6):1139-1147.

110. Sleight P, Yusuf S, Pogue J, et al. Blood-pressure reduction and cardiovascular risk in hope study. Lancet 2001;358(9299): 2130-2131.

111. Investigators HOPES. Effects of ramipril on cardiovascular and microvascular outcomes in people with diabetes mellitus: Results of the hope study and micro-hope substudy. Lancet 2000;355(9200):253-259.

112. Lindholm LH, Ibsen H, Dahlöf B, et al. Cardiovascular morbidity and mortality in patients with diabetes in the losartan intervention for endpoint reduction in hypertension study (life): a randomised trial against atenolol. Lancet 2002;359(9311):1004-1010.

113. Dahlöf B, Devereux RB, Kjeldsen SE, et al. Cardiovascular morbidity and mortality in the losartan intervention for endpoint reduction in hypertension study (LIFE): a randomised trial against atenolol. Lancet 2002;359(9311): 995-1003.

114. Wilkinson IB, Fuchs SA, Jansen IM, et al. Reproducibility of pulse wave velocity and augmentation index measured by pulse wave analysis. J Hypertens 1998;16(12 Pt 2):2079-2084.

115. Meyer ML, Tanaka H, Palta P, et al. Repeatability of central and peripheral pulse wave velocity measures: the atherosclerosis risk in communities (ARIC) study. Am J Hypertens 2015 Jul 31. pii: hpv 127. [Epub ahead of print]. 
116. Cheng HM, Pearson A, Sung SH, Yu WC, Chen CH, Karnon J. Cost-effectiveness of noninvasive central blood pressure monitoring in the diagnosis of hypertension. Am J Hypertens 2015;28(5):604-614.

117. Davies JI, Struthers AD. Pulse wave analysis and pulse wave velocity: a critical review of their strengths and weaknesses. J Hypertens 2003;21(3):463-472.

118. Hlatky M, Greenland P, Arnett D, et al. American heart association expert panel on subclinical atherosclerotic diseases and emerging risk factors and the stroke council. Criteria for evaluation of novel markers of cardiovascular risk: a scientific statement from the American Heart Association. Circulation 2009;119(17):2408-2416.

119. Avolio A. Central aortic blood pressure and management of hypertension: confirmation of a paradigm shift? Hypertens 2013;62(6):1005-1007.

120. McGaughey TJ, Fletcher EA, Shah SA. Impact of antihypertensive agents on central systolic blood pressure and augmentation index: a meta-analysis. Am J Hypertens 2015 Aug 19, pii: hpv 134. [Epub ahead of print].
121. Sharman JE, Marwick TH, Gilroy D, Otahal P, Abhayaratna WP, Stowasser M. Randomized trial of guiding hypertension management using central aortic blood pressure compared with best-practice care principal findings of the BP guide study. Hypertens 2013;62(6):1138-1145.

122. Greenland P, Alpert JS, Beller GA, et al. ACCF/AHA guideline for assessment of cardiovascular risk in asymptomatic adults: a report of the American College of Cardiology Foundation/ American Heart Association task force on practice guidelines developed in collaboration with the American Society of Echocardiography, American Society of Nuclear Cardiology, Society of Atherosclerosis Imaging and Prevention, Society for Cardiovascular Angiography and Interventions, Society of cardiovascular computed tomography, and society for cardiovascular magnetic resonance. J Am College Cardiol 2010;56(25):e50-e103.

123. Van Bortel LM, Laurent S, Boutouyrie P, et al. Expert consensus document on the measurement of aortic stiffness in daily practice using carotid-femoral pulse wave velocity. J Hypertens 2012;30(3):445-448. 